\title{
Is Office Blood Pressure Measurement Reliable in Obese Adolescents?
}

\author{
Derya Tepe (iD) \\ Songül Yılmaz iD ${ }^{2}$ \\ 'Department of Pediatric Endocrology, \\ Ankara Yıldırım Beyazıt Üniversity, \\ Yenimahalle Education and Research \\ Hospital, Ankara, Turkey; ${ }^{2}$ Department of \\ Pediatric Nephrology, Ankara Yıldırım \\ Beyazıt Üniversity, Yenimahalle Education \\ and Research Hospital, Ankara, Turkey
}

\begin{abstract}
Background: Although it is not reflected in the OBP measurement in obese children, ambulatory BP changes are known to occur. MH, non-dipper pattern and nocturnal hypertension have been reported to increase in obese children. On the other hand, the factors that indicate a high risk of hypertension are still unclear. The aim of our study is to especially detect masked hypertension by 24-hour BP measurement in obese adolescents and to evaluate the relationship of masked hypertension with metabolic syndrome parameters, anthropometric measurements and hepatosteatosis in these patients.
\end{abstract}

Methods: A total of 63 adolescents diagnosed with obesity were evaluated between January 2019 and December 2019. Office blood pressure was measured for all children, and all of them underwent ABPM. Patients with and without hypertension in ABPM were compared in terms of clinical and laboratory findings.

Results: The mean age was $14.0 \pm 1.7$ years, females composed $49.2 \%$ of the study population. Office blood pressure measurement revealed hypertension in $4(6.3 \%)$ patients and prehypertension in $15(23.8 \%)$ patients. Thirteen patients $(20.9 \%)$ were diagnosed with masked hypertension, white coat hypertension was diagnosed in 3 (4.7\%) patients. Abnormal ABPM patterns were found to be significantly more frequent in patients with severely obesity (with obesity: $26.4 \%$ vs severe obesity: $55.6 \%$, p = 0.03 ) and patients with a higher waist circumference and waist circumference/height ratio.

Conclusion: The prevalence of masked hypertension in obese adolescents has been found to be quite high. Therefore, we recommend ABPM in adolescents with high waist circumference/height ratio and severe obesity, even if their office blood pressure measurements are normal.

Keywords: adolescent, hypertension, metabolic syndrome, obesity, waist circumference

\section{Introduction}

Childhood obesity is an increasingly important public health problem, especially in developed countries. It has been shown that there is a relationship between obesity and dyslipidaemia, hypertension and insulin resistance. ${ }^{1}$ Obese children are at increased risk for diabetes, coronary artery disease and hypertension not only in childhood but also in adulthood. For this reason, it is very important to be alert in terms of preventing obesity and its accompanying morbidities. ${ }^{2,3}$

Hypertension is one of the most important preventable causes of chronic kidney disease and heart disease. ${ }^{4}$ Although its frequency in children is reported to be 3$5 \%$, it gradually increases with the rise of obesity. Studies have found that the
Correspondence: Songül Yılmaz Department of Pediatric Nephrology, Ankara Yıldırım Beyazıt Üniversity,

Yenimahalle Education and Research Hospital, Ankara, Turkey

Tel +905333558677

Fax +90312587377

Email songulyilmaz23@gmail.com 


\section{Graphical Abstract}

\section{IS OFFICE BLOOD PRESSURE MEASUREMENT RELIABLE IN OBESE ADOLESCENTS?}

HYPOTHESIS: [The presence of masked hypertension can be predicted in obese adolescents.]

DESIGN \& OUTCOMES:

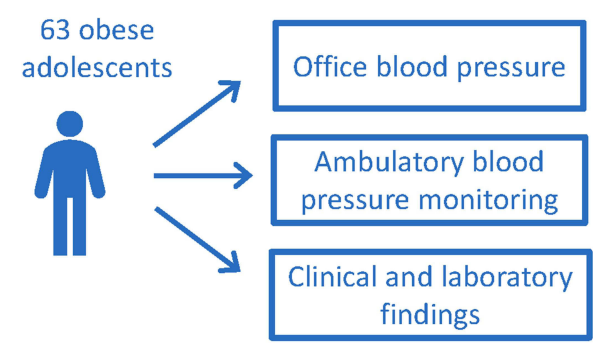

CONCLUSION: We suggest that ambulatory blood pressure measurements should be performed even if the office blood pressure measurements of severely obese adolescents, especially with a high WHR, are normal.

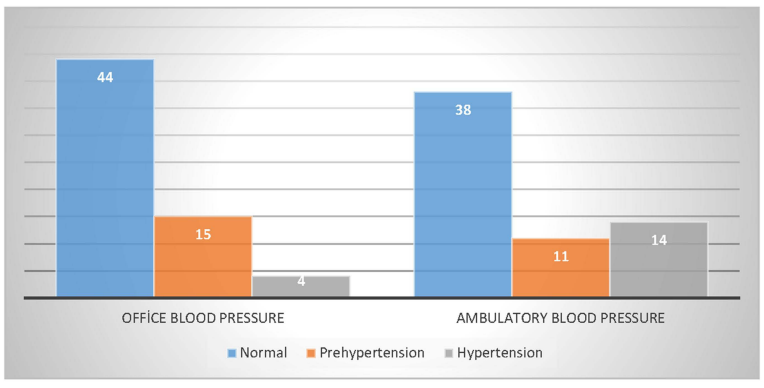

- in severely obese group

- With high waist circumference / height ratio

ABPM abnormalities

- Prehypertension in office blood presure measurement possibility of developing hypertension in obese children is three times higher than that in non-obese children. ${ }^{5}$ Early recognition and treatment of hypertension is critical in preventing end organ damage. ${ }^{4}$ For this reason, obese children should be evaluated with a blood pressure measurement at each visit. ${ }^{6}$ However, with office blood pressure (OBP) measurement, hypertension may be overlooked, and the distinction cannot be made between white coat hypertension (WCH) and masked hypertension $(\mathrm{MH})$. Therefore, the gold standard in the diagnosis of hypertension is ambulatory blood pressure monitoring (ABPM) ${ }^{7}$

Although it is not reflected in the OBP measurement in obese children, ambulatory $\mathrm{BP}$ changes are known to occur. $\mathrm{MH}$, non-dipper pattern and nocturnal hypertension have been reported to increase in obese children. ${ }^{8-10}$ Since ABPM in all obese children involves technical and financial problems, it is very important to determine which obese child will undergo ABPM. ${ }^{11}$ Unfortunately, there is no clear recommendation on this matter. The aim of our study is to especially detect MH by 24-hour BP measurement in obese adolescents and to evaluate the relationship of MH with metabolic syndrome parameters, anthropometric measurements and hepatosteatosis in these patients. In this way, it was aimed to evaluate the factors that associated with ambulatory hypertension in obese adolescents.

\section{Materials and Methods \\ Patients}

Obese adolescents aged 12-18 years who were admitted to the Paediatric Endocrinology outpatient clinic of Ylldırım Beyazit University Yenimahalle Training and Research Hospital between January 2019 and December 2019 were included in the study. Detailed information about the study was given to the patient and his/her family, and written informed consent was obtained from the families who accepted. This study was approved by the The Research Ethics Committee of Ankara Yıldırım Beyazit University School of Medicine approved the study (Date: 2019, number: 79). This study was conducted in accordance with the Declaration of Helsinki.

Patients using drugs and having chronic diseases (such as kidney, heart disease, and hyperthyroidism/hypothyroidism) were excluded from the study. Information about the study was given to 66 patients meeting the specified 
conditions. The study was conducted with 63 patients, since three patients did not agree to participate in the study. Detailed history (delivery type, birth weight, and maturation status) was taken from the patients. The family history of hypertension and diabetes was questioned. Physical examination findings and (acanthosis nigricans and puberty stage) of the patients were noted.

\section{Anthropometric Measurements}

The weight, height and waist circumference (WC) of all patients were measured. Body weight and height percentiles and body mass index (BMI) percentiles were calculated according to age and sex. ${ }^{12}$ BMI (in $\mathrm{kg} / \mathrm{m} 2$ ) was calculated as body weight in kilograms divided by height in square meters. Obesity is defined as a BMI $\geq 95$ th percentile for age and sex, respectively. ${ }^{13,14}$ The WC was measured with the subject standing, midway between the lowest rib margin and the iliac crest, using a flexible nonstretch tape measure with a precision of $1 \mathrm{~mm}$. Relative weight (RW) and waist circumference/height ratio (WHtR) were calculated. The WHtR was calculated by dividing WC (in $\mathrm{cm}$ ) by height (in $\mathrm{cm}$ ), and the cut-off used was 0.54 for both sexes. ${ }^{14}$ A BMI at least $120 \%$ of the 95 th percentile for age or more than $35 \mathrm{~kg} / \mathrm{m} 2$ was recommended for defining severe obesity. ${ }^{13}$ The patients were grouped as obese and severely obese. The two groups were compared in terms of BP levels.

\section{Laboratory and Radiological Findings}

Fasting and postprandial blood glucose, insulin, lipid panel, liver function tests and kidney function tests were evaluated from the patient files. Homeostasis model assessment for insulin resistance (HOMA-IR) index was estimated from fasting serum glucose and insulin levels using the HOMA Calculator version 2.2.3 (Oxford Center for Diabetes, Endocrinology and Metabolism, Oxford, UK) for insulin resistance in patients, and the threshold value was accepted as 3.16 according to guidelines. ${ }^{15}$ Dyslipidaemia was defined according to the classification of the American Heart Association, corresponding to the 95th percentile in a American population, as total cholesterol $>5.2 \mathrm{mmol} / \mathrm{L}$ (200 mg/dL), Low density lipoprotein (LDL) cholesterol > $3.4 \mathrm{mmol} / \mathrm{L}(130 \mathrm{mg} / \mathrm{dL})$, high density lipoprotein(HDL) cholesterol $<0.9 \mathrm{mmol} / \mathrm{L}(35 \mathrm{mg} / \mathrm{dL})$, or triglycerides $>1.7$ $\mathrm{mmol} / \mathrm{L}(150 \mathrm{mg} / \mathrm{dL})$, or a combination thereof. ${ }^{16}$ Based on reference levels of ALT kits used in our hospital laboratory, ALT levels $>22 \mathrm{U} / \mathrm{L}$ in females and $>25 \mathrm{U} / \mathrm{L}$ in males were regarded as elevated liver enzymes. ${ }^{16}$
The diagnosis of metabolic syndrome was made according to International Diabetes Federation (IDF) criteria, which require the presence of abdominal obesity (WC $>90$ th percentile) and at least two of the following criteria: high blood glucose ( $\geq 100 \mathrm{mg} / \mathrm{dL}$ ), low HDL cholesterol $(<40 \mathrm{mg} / \mathrm{dL})$, high triglycerides $(\geq 150 \mathrm{mg} /$ $\mathrm{dL}$ ) or hypertension (systolic BP (SBP) $>130 \mathrm{mmHg}$ and/ or diastolic BP (DBP) $>85 \mathrm{mmHg}$ ) between 10 and 16 years of age. For children $>16$ years old, metabolic syndrome criteria were the same, except for HDL cholesterol levels (HDL $<40 \mathrm{mg} / \mathrm{dL}$ in males and $<50 \mathrm{mg} / \mathrm{dL}$ in females). ${ }^{17}$ Waist circumference values prepared by Hatipoğlu et al for Turkish children were used for waist circumference percentile values. ${ }^{18}$ Hepatobiliary ultrasonography (USG) was performed in all patients in terms of hepatosteatosis.

\section{Office Blood Pressure}

All children underwent an OBP measurement on three different occasions with an appropriate sphygmomanometer. The mean value of three blood pressure measurements was calculated. Office blood pressures were obtained by auscultation according to published guidelines. For casual BP measurements, HT was diagnosed when the mean office BP was greater than the 95th percentile for age, sex, and height in children under the age of 13 years old, or $>130 / 80 \mathrm{mmHg}$ in children $\geq 13$ years of age, according to the American Academy of Pediatrics 2017 hypertension guideline. ${ }^{19}$

\section{Ambulatory Blood Pressure Monitoring}

All children underwent ABPM with the "Spacelabs Healthcare OnTrak Ambulatory Blood Pressure Monitor". The guideline was used to select a suitably sized cuff placed on the non-dominant arm to allow daily activities. ${ }^{20}$ The monitoring was programmed to record BP every $20 \mathrm{~min}$ while awake and every $30 \mathrm{~min}$ while asleep according to the guideline. The ABPM device was calibrated before each test. ABPM measurements were checked with another sphygmomanometer at the beginning of the test. At least one valid reading per hour was required for the study to be considered adequate, with at least 40 readings over a 24 -h period. The following parameters were assessed: mean arterial pressure (MAP) and average SBP and DBP, day to night differences and average heart rates, and BP loads. These parameters were assessed for $24 \mathrm{~h}$, and the daytime and nighttime data were analysed separately. BP load was 
estimated as the percentage of readings over the hypertension threshold. Decrement of mean SBP or DBP over $10 \%$ between daytime and nighttime measurements was defined as dipping. ${ }^{7}$ The standard deviation score (SDS) was calculated for both office and ambulatory BPs to standardize measurements according to age and gender. The patients were divided into four groups, categorized as normotension, prehypertension, hypertension, and severe hypertension as recommended in the 2014 American Heart Association paediatric ABPM guideline. WCH is defined as casual/office BP levels $\geq 95$ th percentile but normal outside of a clinical setting, and $\mathrm{MH}$ is defined as a normal clinic BP but elevated ambulatory $\mathrm{BP}^{20}$ Patients with a mean ambulatory BP of $<95 \mathrm{p}$ and a blood pressure load of $<25 \%$ were considered prehypertension. ${ }^{7}$ Patients with and without abnormal ABPM patterns were compared in terms of clinical and laboratory findings. ABPM results evaluated as prehypertension and hypertension were defined as ABPM abnormality.

\section{Statistical Analysis}

Statistical analysis was performed using IBM Statistical Package for the Social Sciences version 23.0 (IBM SPSS Corp.; Armonk, NY, USA) statistical package program. The Kolmogorov-Smirnov test was conducted to assess the distribution of the variables. Descriptive statistics were given as mean \pm standard deviation (SD) for numerical data with normal distribution and as percentages for categorical data. Differences in variables between groups were evaluated by $t$-test or analysis of variance (ANOVA). A p-value of $<0.05$ was considered significant.

\section{Results}

The study population consisted of 31 girls and 32 boys. The mean age was $14.0 \pm 1.7$ years. Approximately threequarters of the patients had family obesity and one-third had hypertension in the family. The demographic findings of the patients are shown in Table 1 .

HOMA-IR was $\geq 3.16$ in 37 patients (58.7\%). HOMAIR levels were found to be significantly higher in severely obese patients. Twenty-two patients had elevations in their liver function tests, 22 patients (34.9\%) had dyslipidaemia. Metabolic syndrome was diagnosed in four patients. However, when it was reviewed on the basis of ambulatory BP levels, 13 new patients were found to meet the criteria for metabolic syndrome. Metabolic syndrome was observed more frequently in severely obese adolescents, but this difference did not reach a statistically significant
Table I Demographic Features of Adolescents

\begin{tabular}{|c|c|c|c|}
\hline & $\begin{array}{l}\text { Obese } \\
\text { Group } \\
n=34(\%)\end{array}$ & $\begin{array}{l}\text { Severely Obese } \\
\text { Group n = } 29(\%)\end{array}$ & $\mathbf{p}$ \\
\hline & Mean士SD & Mean士SD & \\
\hline $\begin{array}{l}\text { Gender } \\
\text { Female }\end{array}$ & 12 (38.7\%) & 19 (65.5\%) & 0.02 \\
\hline Age (year) & $13.9 \pm 1.6$ & $14.2 \pm 1.9$ & 0.47 \\
\hline Birth weight $(\mathrm{kg})$ & $3.32 \pm 1.2$ & $4.31 \pm 1.9$ & 0.33 \\
\hline $\begin{array}{l}\text { Weight (kg) } \\
\text { SDS }\end{array}$ & $\begin{array}{l}76.05 \pm 10.9 \\
2.1 \pm 0.55\end{array}$ & $\begin{array}{l}89.37 \pm 12.7 \\
3.3 \pm 0.67\end{array}$ & $\begin{array}{l}<0.001 \\
<0.001\end{array}$ \\
\hline $\begin{array}{l}\text { Height }(\mathrm{cm}) \\
\text { SDS }\end{array}$ & $\begin{array}{l}161.9 \pm 9.7 \\
0.39 \pm 1.1\end{array}$ & $\begin{array}{l}162.8 \pm 8.1 \\
0.49 \pm 0.96\end{array}$ & $\begin{array}{l}0.69 \\
0.69\end{array}$ \\
\hline BMI $\left(\mathrm{kg} / \mathrm{m}^{2}\right)$ & $28.8 \pm 2.0$ & $33.5 \pm 3.0$ & $<0.001$ \\
\hline $\begin{array}{l}\text { Waist } \\
\text { circumference }(\mathrm{cm})\end{array}$ & $92.6 \pm 7.0$ & $100.3 \pm 7.6$ & $<0.001$ \\
\hline $\begin{array}{l}\text { Acanthosis } \\
\text { nigricans }\end{array}$ & II (32.4\%) & $16(55.2 \%)$ & 0.06 \\
\hline
\end{tabular}

Abbreviations: BMI, body mass index; SDS, standard deviation score.

level. Hepatosteatosis was observed in 25 patients (39\%), and the frequency of hepatosteatosis was higher in the severely obese group. Laboratory and radiological findings of the patients are summarized in Table 2.

In OBP measurements, four patients had hypertension. In these four patients with hypertension, there was a diagnosis of prehypertension in two patients, $\mathrm{WCH}$ in one patient, and hypertension in one patient, which were made by ABPM. In OBP measurements, 15 patients had prehypertension, and in these patients, two patients had prehypertension and six patients had $\mathrm{MH}$, which were diagnosed by ABPM. The OBP measurements of 44 patients were within the normal range. With ABPM, seven of these patients were diagnosed with prehypertension and seven of them were diagnosed with $\mathrm{MH}$. As a result, 13 patients were diagnosed with $\mathrm{MH}$, and three patients were diagnosed with WCH by ABPM. In Figure 1, patients are grouped according to their office and ambulatory BP measurements.

Of the 14 patients diagnosed with hypertension with ABPM, 10 had end-organ damage (8 cardiac hypertrophy, 2 hypertensive retinopathy, both in 2 patients). These patients were started on antihypertensive treatment. Since there was no end organ damage in four patient, it was planned to follow-up blood pressures with lifestyle 
Table 2 Laboratory and Radiological Findings of the Patients

\begin{tabular}{|c|c|c|c|}
\hline & $\begin{array}{l}\text { Obese } \\
\text { Group } \\
\mathrm{n}=\mathbf{3 4}(\%)\end{array}$ & $\begin{array}{l}\text { Severely } \\
\text { Obese Group } \\
n=29(\%)\end{array}$ & $\mathbf{p}$ \\
\hline & Mean士SD & Mean士SD & \\
\hline Fasting glucose $(\mathrm{mg} / \mathrm{dl})$ & $87.3 \pm 6.1$ & $87.0 \pm 7.0$ & 0.83 \\
\hline Postprandial glucose $(\mathrm{mg} / \mathrm{dl})$ & $90.8 \pm 11.4$ & $90.8 \pm 12.7$ & 085 \\
\hline Fasting insülin $(0-25 \mu \mathrm{lU} / \mathrm{mL})$ & $15.1 \pm 5.1$ & $20.0 \pm 8.8$ & 0.008 \\
\hline $\begin{array}{l}\text { Postprandial insülin (22-79 } \\
\mu \mathrm{lU} / \mathrm{mL})\end{array}$ & $77.0 \pm 11.2$ & $89.3 \pm 12.9$ & 0.4 \\
\hline HOMA-IR & $3.3 \pm 1.2$ & $4.3 \pm 1.9$ & 0.01 \\
\hline Total cholesterol (mg/dl) & $168.7 \pm 28.9$ & $170.0 \pm 30.3$ & 0.85 \\
\hline Triglycerides (mg/dL) & $116.7 \pm 42.6$ & $113.8 \pm 40.4$ & 0.78 \\
\hline LDL cholesterol $(\mathrm{mg} / \mathrm{dL})$ & $103.2 \pm 25.9$ & $104.1 \pm 24.8$ & 0.89 \\
\hline HDL cholesterol (mg/dL) & $42.9 \pm 6.9$ & $42.3 \pm 8.3$ & 0.75 \\
\hline $\mathrm{ALT}(\mathrm{U} / \mathrm{L})$ & $23.5 \pm 17.9$ & $25.5 \pm 10.5$ & 0.61 \\
\hline AST (U/L) & $23.8 \pm 9.4$ & $23.2 \pm 5.6$ & 0.74 \\
\hline $\begin{array}{l}\text { Hepatosteatosis } \\
\text { Grade I } \\
\text { Grade } 2 \\
\text { Grade } 3\end{array}$ & $\begin{array}{l}8(23.5 \%) \\
3(8.8 \%) \\
1(2.9 \%)\end{array}$ & $\begin{array}{l}9(31 \%) \\
4(13.8 \%) \\
-\end{array}$ & $>0.05$ \\
\hline $\begin{array}{l}\text { Metabolic syndrome } \\
\text { According to OBP } \\
\text { According to ABPM }\end{array}$ & $\begin{array}{l}\text { I (2.9\%) } \\
5 \text { (14.7\%) }\end{array}$ & $\begin{array}{l}3(10.3 \%) \\
8(27.5 \%)\end{array}$ & 0.11 \\
\hline
\end{tabular}

Abbreviations: OBP, office blood pressure; ABPM, ambulatory blood pressure monitoring.

changes. The renal function tests of all patients were normal, and proteinuria was not detected in any of them.

When ABPM results were compared by obesity severity, BP abnormalities (prehypertension and hypertension) were found in 16 severely obese children (55.1\%) and in nine obese children (26.4\%). Abnormalities in ABPM were found to be higher in severely obese children ( $p$ : $0.03)$; 46 patients $(73.0 \%)$ had no decrease in BP at night. No significant relationship was found between the degree of obesity of the patients and the non-dipper pattern ( $p \geq 0.05$ ). The ABPM findings of the patients are shown in Table 3.

WC and WHtR were found to be higher in patients with BP abnormalities in ABPM $(\mathrm{p}=0.021$ and $\mathrm{p}=0.004$, respectively). BP abnormalities were observed in $51 \%$ of 35 patients with a WHtR of 0.54 and above and in $25 \%$ of 28 patients with a WHtR $<0.54$. Patients with a WHtR $\geq 0.54$ had 3.1 times more ABPM abnormalities than patients with lower ones ( $\mathrm{p}=0.03$, odds ratio: $1.87-9.3$ ). The office systolic and diastolic BP levels of patients with abnormal blood pressures in ABPM were found to be higher than those with normal ABPM $(\mathrm{p}=<0.001$ and $\mathrm{p}=0.01$, respectively). There were no differences between the two groups in terms of other clinic and laboratory characteristics.

\section{Discussion}

In this study, ABPM was performed in obese adolescents and OBP was compared with ABPM and the factors that associated with ambulatory hypertension were investigated. ABPM abnormalities were demonstrated in 39\% of patients. Thirteen patients $(20.9 \%)$ were diagnosed with $\mathrm{MH}$, and three patients (4.7\%) were diagnosed with WCH. ABPM abnormalities were found more often in severely obese patients. In addition, WC, WHtR and systolic and diastolic OBPs were found to be higher in patients with ABPM abnormalities.

Overweight and obesity have been increasing rapidly over the last three decades, and this parallels the rise in BP. Data from the US NHANES have revealed that $33.6 \%$ of adolescents aged 12-19 years were overweight or obese. ${ }^{21}$ Many studies have shown an increase in BP levels in children with high BMI. ${ }^{8,10,22-24}$ The increase in the number of obese children causes hypertension and related comorbidities to be seen more frequently. In a study conducted with high school students, an increase in BP was found in more than $30 \%$ of obese adolescents. ${ }^{25}$ In our study, similar to the literature, the frequency of hypertension among obese children was found to be $22 \%$, and ABPM abnormalities were observed in almost $40 \%$. These data show that obese children should be closely monitored for hypertension.

Although the classic method in the diagnosis of hypertension is OBP measurement, it may be insufficient for the diagnosis of $\mathrm{WCH}$ and $\mathrm{MH}{ }^{19,20}$ Since the 1980 s, many studies have shown that abnormal circadian BP rhythm is associated with cardiovascular diseases. ${ }^{26-28}$ Therefore, ABPM is very important in the diagnosis and follow-up of hypertension. ${ }^{7}$ It has been shown that ambulatory blood pressure changes are more common in obese children. ${ }^{10,29-31}$ Hvidt et $\mathrm{al}^{29}$ compared the ABPM parameters of 92 obese and 49 healthy children 10-18 years old and demonstrated BP levels at night were higher in obese children compared to those in children of a healthy weight, independently of insulin resistance. The authors stated that hypertension at night is risky in terms of end 


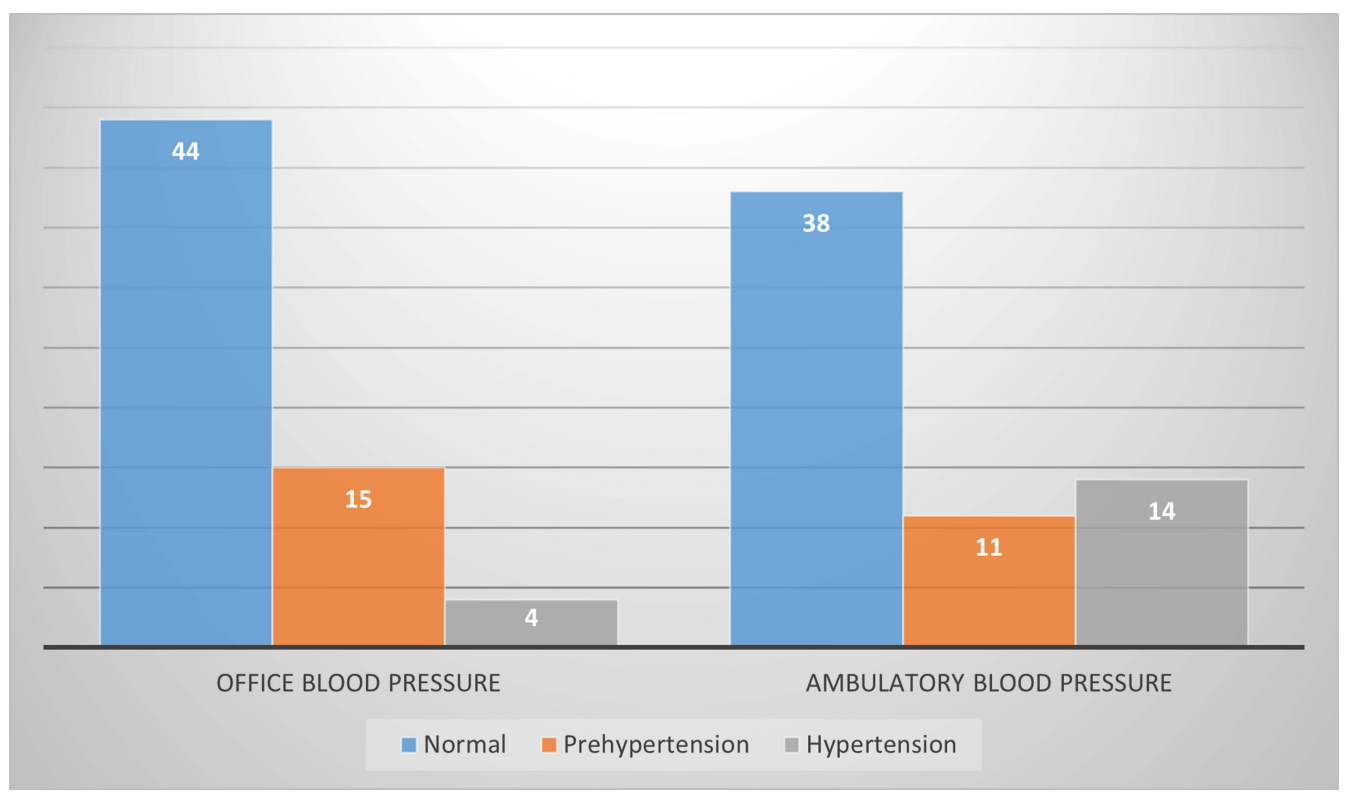

Figure I Comparison of office and ambulatory blood pressure measurements of patients.

organ damage and suggested that ABPM may be beneficial in obese children for early diagnosis. There is also evidence that screening adult obese with ABPM is costeffective. ${ }^{32}$ Although there is no study on costs in children, it seems reasonable to screen all obese children with ABPM, if possible, in terms of early diagnosis. However, there may not be enough opportunities to perform ABPM in all obese children, especially in developing countries. Therefore it is important to select patients who will undergo ABPM. In a study in which ABPM was performed on 72 obese children, the frequency of ambulatory hypertension was found to be $48.6 \%$, and nocturnal DBP levels were higher in children with a BMI $z$ score $>3$ SDS. ${ }^{30}$ In our study, hypertension was detected in 14 patients with normal OBPs, and antihypertensive medication was initiated in two of these patients due to end organ damage. Thirteen patients were diagnosed with $\mathrm{MH}$ and three patients were diagnosed with WCH. Also, a nondipper pattern was seen in more than $70 \%$ of the patients. ABPM abnormalities were found more frequently in severely obese adolescents. For this reason, we recommend that severely obese adolescents should be more careful in terms of hypertension and consider ambulatory BP assessment.

The metabolic syndrome includes many cardiovascular risk factors ("hypertension, altered glucose metabolism, dyslipidaemia, and abdominal obesity"). With the increase of obesity in childhood, metabolic syndrome is more common. ${ }^{17}$ It has been reported that its frequency may reach up to $44 \%$ among obese children. ${ }^{33}$ Consequently, the metabolic syndrome in children has become a global public health problem. The research focus of the metabolic syndrome has shifted to its prevention in early life. ${ }^{34,35}$ In our study, the frequency of metabolic syndrome with ABPM increased from $6.3 \%$ to $25.3 \%$. If these patients are evaluated only with OBP measurements, the metabolic syndrome will not be identified in 13 patients, and this will cause delays in diagnosis and treatment. Therefore, attention should be paid in terms of metabolic syndrome in obese children, and ABPM should be kept in mind in patients with one of the other risk factors (insulin resistance, abdominal obesity, or dyslipidaemia), even if they are normotensive.

Prehypertension was first used in the fourth report in 2004 to describe children with higher than normal BP but lower than the hypertension threshold. ${ }^{6}$ It has been reported that these patients should be closely monitored and will progress to hypertension over time. ${ }^{35-37}$ Falkner et $\mathrm{al}^{36}$ have determined that about $7 \%$ per year progressed from pre-HTN to HTN.

It has been reported that $14 \%$ of adolescents with prehypertension develop hypertension after 2 years, and the incidence of hypertension in obese adolescents after 2 years is $68 \%$ in boys and $43 \%$ in girls. ${ }^{38}$ It has also been demonstrated that prehypertensive children have higher markers of inflammation than those in 
Table 3 ABPM Data of Patients According to Degree of Obesity Degree

\begin{tabular}{|c|c|c|c|}
\hline & $\begin{array}{l}\text { Obese Group } \\
n=34 \text { (\%) }\end{array}$ & $\begin{array}{l}\text { Severely } \\
\text { Obese Group } \\
n=29(\%)\end{array}$ & $\mathbf{P *}$ \\
\hline & Mean士SD & Mean士SD & \\
\hline Office SBP & $116.2 \pm 8.1$ & $116.0 \pm 9.0$ & 0.93 \\
\hline SDS & 0.63 & 0.70 & 0.71 \\
\hline Office DBP & $67.7 \pm 6.8$ & $72.1 \pm 8.3$ & 0.02 \\
\hline SDS & 0.27 & 0.7 & 0.01 \\
\hline 24-hour MAP & $82.7 \pm 9.9$ & $89.1 \pm 10.8$ & 0.018 \\
\hline SDS & -0.08 & 1.3 & 0.008 \\
\hline Mean 24-hour SBP & $112.7 \pm 13.0$ & $122.3 \pm 15.9$ & 0.02 \\
\hline SDS & $\mathrm{I} .4$ & 1.9 & 0.006 \\
\hline Mean 24-hour DBP & $66.1 \pm 6.1$ & $73.7 \pm 11.6$ & 0.02 \\
\hline SDS & -0.2 & I.I & 0.01 \\
\hline Daytime MAP & $83.8 \pm 9.8$ & $90.8 \pm 10.4$ & 0.008 \\
\hline SDS & -0.3 & 0.9 & 0.001 \\
\hline Mean daytime SBP & $114.7 \pm 15.6$ & $123.8 \pm 14.0$ & 0.01 \\
\hline SDS & -0.6 & 1.7 & 0.04 \\
\hline Load (\%) & 17.8 & 32.0 & 0.003 \\
\hline Mean daytime DBP & $68.7 \pm 8.6$ & $75.1 \pm 10.7$ & 0.01 \\
\hline SDS & -0.5 & 1.9 & 0.01 \\
\hline Load (\%) & 16.1 & 26.7 & 0.03 \\
\hline Nighttime MAP & $77.4 \pm 12.1$ & $82.3 \pm 10.8$ & 0.09 \\
\hline SDS & I.I & 1.7 & 0.28 \\
\hline Mean nighttime SBP & $108.4 \pm 15.5$ & $116.2 \pm 13.8$ & 0.04 \\
\hline SDS & 0.54 & 1.5 & 0.01 \\
\hline Load (\%) & 24.5 & 48 & 0.05 \\
\hline Mean nighttime DBP & $60.8 \pm 11.1$ & $64.7 \pm 11.1$ & 0.17 \\
\hline SDS & 0.7 & 1.4 & 0.16 \\
\hline Load (\%) & 27.5 & 44.5 & 0.03 \\
\hline Dipping SKB (\%) & $7.9 \pm 3.0$ & $5.0 \pm 1.9$ & 0.44 \\
\hline DKB (\%) & $11.4 \pm 1.9$ & $12.4 \pm 2.4$ & 0.73 \\
\hline ABPM abnormality & & & 0.03 \\
\hline Prehypertension & 4 (II.7\%) & 7 (24.1\%) & \\
\hline Hypertension & $5(14.7 \%)$ & 9 (3I\%) & \\
\hline
\end{tabular}

Notes: *Significant $\mathrm{p}$ levels are shown in bold. Units of all blood pressure levels are given in "mmHg".

Abbreviations: SDS, standard deviation score; MAP, mean arterial blood pressure; SBP, systolic blood pressure; DBP, diastolic blood pressure.

normotensive children and that the cardiovascular mortality of these patients is increased. ${ }^{39}$ Therefore, careful follow-up of prehypertensive children is very important to prevent this progression. In our study, 15 adolescents were diagnosed with prehypertension in OBP measurements, and more than half of them showed ABPM abnormalities. In addition, patients with ABPM abnormalities had higher office systolic and diastolic BP levels. Therefore, obese adolescents with prehypertension should be followed closely, and ABPM should be performed if possible for early diagnosis and treatment.

It has long been known that central obesity increases the risk of cardiovascular morbidity. In recent years, an increasing number of studies have been published showing that a high WHtR predicts metabolic syndrome in children and adolescents, and it can be an alternative to BMI in determining cardiometabolic risk. ${ }^{40-43}$ In the study of Vieria et al, ${ }^{44}$ it was stated that WHtR predicts obesity and abdominal fat in children aged 4-7 years, and this parameter should definitely be evaluated in terms of obesity diagnosis. In another study, it was found that inflammation and endothelial dysfunction indicators were higher in children with an increased WHtR, and it was reported that the BP of these children was higher than healthy children. ${ }^{43}$ It has been suggested that the WHtR is also important for hypertension. ${ }^{14,42,43}$ Madruga et $\mathrm{al}^{42}$ evaluated 1030 adolescents, one-third of whom were obese, and the frequency of hypertension was found to be $30 \%$. It was also found that the frequency of HT increased 2.4 times in patients with a WHtR $>0.50$. In another recent study, 678 adolescents were evaluated, and it was emphasized that a WHtR > 0.54 is an appropriate parameter to predict metabolic syndrome. ${ }^{14}$ Similarly, in our study, WC and WHtR were found to be significantly higher in patients with high ambulatory BP. In addition, ABPM abnormalities were 3 times higher in children with a WHtR $\geq 0.54$. Therefore, we think that obese children (especially with a higher WHtR) should be more alert in terms of hypertension.

The small number of patients, the absence of a control group and follow-up of prehypertensive patients are among the limitations of our study. In addition, prehypertensive children were not evaluated for end organ damage. On the other hand, our study is very important in terms of not overlooking obese adolescents with high risk for $\mathrm{MH}$ in daily practice and making an early diagnosis.

In conclusion, in our study, by performing ABPM on obese adolescents, a higher incidence of ambulatory BP abnormalities was observed in the severely obese group and in children with a WHtR $\geq 0.54$. In addition, ABPM abnormalities were found in one-third of the children with normal OBPs. These results imply that, by being satisfied 
with OBP assessment, the BP abnormalities seen in onethird of obese adolescents might be missed. Therefore, we suggest that ABPM should be performed, even if the OBP measurements of all obese adolescents are normal, if possible. It should be kept in mind that those who are severely obese and have a high WHtR are more likely to have MH.

\section{Disclosure}

The authors report no conflicts of interest in this work.

\section{References}

1. Kumar S, Kelly AS. Review of childhood obesity: from epidemiology, etiology, and comorbidities to clinical assessment and treatment. Mayo Clin Proc. 2017;92(2):251-265. doi:10.1016/j.mayocp.2016. 09.017

2. Ayer J, Charakida M, Deanfield JE, Celermajer DS. Lifetime risk: childhood obesity and cardiovascular risk. Eur Heart J. 2015;36 (22):1371-1376. doi:10.1093/eurheartj/ehv089

3. Llewellyn A, Simmonds M, Owen CG, Woolacott N. Childhood obesity as a predictor of morbidity in adulthood: a systematic review and meta-analysis. Obes Rev. 2016;17(1):56-67. doi:10.1111/obr. 12316

4. Rao G. Diagnosis, epidemiology, and management of hypertension in children. Pediatrics. 2016;138(2):e20153616. doi:10.1542/peds.20153616

5. Sorof J, Daniels S. Obesity hypertension in children: a problem of epidemic proportions. Hypertension. 2002;40(4):441-447. doi:10.11 61/01.HYP.0000032940.33466.12

6. Falkner B, Daniels SR, Flynn JT, et al.The fourth report on the diagnosis, evaluation, and treatment of high blood pressure in children and adolescents. Pediatrics. 2004;114(Suppl 2):555-576. doi:10.1542/peds.114.2.S2.555

7. Macumber I. Ambulatory blood pressure monitoring in children and adolescents: a review of recent literature and new guidelines. Curr Hypertens Rep. 2017;19(12):96. doi:10.1007/s11906-017-0791-5

8. Asayama K, Sato A, Ohkubo T, et al. The association between masked hypertension and waist circumference as an obesity-related anthropometric index for metabolic syndrome: the Ohasama study. Hypertens Res. 2009;32(6):438-443. doi:10.1038/hr.2009.37

9. Eguchi K. Ambulatory blood pressure monitoring in diabetes and obesity-a review. Int J Hypertens. 2011;2011:954757. doi:10.4061/ 2011/954757

10. Macumber IR, Weiss NS, Halbach SM, Hanevold CD, Flynn JT. The association of pediatric obesity with nocturnal non-dipping on 24-hour ambulatory blood pressure monitoring. Am J Hypertens. 2016;29(5):647-652. doi:10.1093/ajh/hpv147

11. Sanchez RA, Boggia J, Penaherrera E, et al. Ambulatory blood pressure monitoring over $24 \mathrm{~h}$ : a Latin American Society of Hypertension position paper-accessibility, clinical use and cost effectiveness of ABPM in Latin America in year 2020. J Clin Hypertens (Greenwich). 2020;22(4):527-543. doi:10.1111/jch.13816

12. Neyzi O, Bundak R, Gokcay G, et al. Reference values for weight, height, head circumference, and body mass index in Turkish children. J Clin Res Pediatr Endocrinol. 2015;7(4):280-293. doi:10.4274/ jcrpe. 2183

13. Styne DM, Arslanian SA, Connor EL, et al. Pediatric obesity-assessment, treatment, and prevention: an endocrine society clinical practice guideline. J Clin Endocrinol Metab. 2017;102 (3):709-757.

14. Mishra PE, Shastri L, Thomas T, et al. Waist-to-height ratio as an indicator of high blood pressure in urban Indian school children. Indian Pediatr. 2015;52(9):773-778. doi:10.1007/s13312-015-0715-x
15. Keskin M, Kurtoglu S, Kendirci M, Atabek ME, Yazici C. Homeostasis model assessment is more reliable than the fasting glucose/insulin ratio and quantitative insulin sensitivity check index for assessing insulin resistance among obese children and adolescents. Pediatrics. 2005;115 (4):e500-e503. doi:10.1542/peds.2004-1921

16. Kavey RE, Daniels SR, Lauer RM, Atkins DL, Hayman LL, Taubert K. American Heart Association guidelines for primary prevention of atherosclerotic cardiovascular disease beginning in childhood. Circulation. 2003;107(11):1562-1566. doi:10.1161/01. CIR.0000061521.15730.6E

17. Zimmet P, Alberti KG, Kaufman F, et al. The metabolic syndrome in children and adolescents - an IDF consensus report. Pediatr Diabetes. 2007;8(5):299-306. doi:10.1111/j.1399-5448.2007.00271.x

18. Hatipoglu N, Ozturk A, Mazicioglu MM, Kurtoglu S, Seyhan S, Lokoglu F. Waist circumference percentiles for 7- to 17-year-old Turkish children and adolescents. Eur J Pediatr. 2008;167 (4):383-389. doi:10.1007/s00431-007-0502-3

19. Flynn JT, Kaelber DC, Baker-Smith CM, et al. Clinical practice guideline for screening and management of high blood pressure in children and adolescents. Pediatrics. 2017;140(3):e20171904. doi:10.1542/peds.2017-1904

20. Flynn JT, Urbina EM. Pediatric ambulatory blood pressure monitoring: indications and interpretations. J Clin Hypertens (Greenwich). 2012;14(6):372-382. doi:10.1111/j.1751-7176.2012.00655.x

21. Ogden CL, Carroll MD, Kit BK, Flegal KM. Prevalence of obesity and trends in body mass index among US children and adolescents, 1999-2010. JAMA. 2012;307(5):483-490. doi:10.1001/jama.2012.40

22. Duncan MJ, James L, Griffiths L. The relationship between resting blood pressure, body mass index and lean body mass index in British children. Ann Hum Biol. 2011;38(3):324-329. doi:10.3109/ 03014460.2010.546811

23. Duncan MJ, Mota J, Vale S, Santos MP, Ribeiro JC. Associations between body mass index, waist circumference and body shape index with resting blood pressure in Portuguese adolescents. Ann Hum Biol. 2013;40(2):163-167. doi:10.3109/03014460.2012.752861

24. Larsson C, Hernell O, Lind T. Moderately elevated body mass index is associated with metabolic variables and cardiovascular risk factors in Swedish children. Acta Paediatr. 2011;100(1):102-108. doi:10.1111/j.1651-2227.2010.01969.x

25. McNiece KL, Poffenbarger TS, Turner JL, Franco KD, Sorof JM, Portman RJ. Prevalence of hypertension and pre-hypertension among adolescents. J Pediatr. 2007;150(6):640-644, 644 e641. doi:10.1016/ j.jpeds.2007.01.052

26. Bjelakovic B, Jaddoe VW, Vukomanovic V, et al. The relationship between currently recommended ambulatory systolic blood pressure measures and left ventricular mass index in pediatric hypertension. Curr Hypertens Rep. 2015;17(4):534. doi:10.1007/s11906-015-0534-4

27. Hansen TW, Li Y, Boggia J, Thijs L, Richart T, Staessen JA. Predictive role of the nighttime blood pressure. Hypertension. 2011;57(1):3-10. doi:10.1161/HYPERTENSIONAHA.109.133900

28. Verdecchia P, Angeli F, Mazzotta G, et al. Day-night dip and early-morning surge in blood pressure in hypertension: prognostic implications. Hypertension. 2012;60(1):34-42. doi:10.1161/ HYPERTENSIONAHA.112.191858

29. Hvidt KN, Olsen MH, Holm JC, Ibsen H. Obese children and adolescents have elevated nighttime blood pressure independent of insulin resistance and arterial stiffness. Am J Hypertens. 2014;27 (11):1408-1415. doi:10.1093/ajh/hpu055

30. Renda R. Comparison of ambulatory blood pressure monitoring and office blood pressure measurements in obese children and adolescents. Acta Clin Belg. 2018;73(2):126-131. doi:10.1080/ 17843286.2017.1390536

31. So HK, Yip GW, Choi KC, et al. Association between waist circumference and childhood-masked hypertension: a community-based study. J Paediatr Child Health. 2016;52(4):385-390. doi:10.1111/ jpc. 13121 
32. Costa D, Peixoto Lima R. Cost-effectiveness of ambulatory blood pressure monitoring in the management of hypertension. Rev Port Cardiol. 2017;36(2):129-139. doi:10.1016/j.repc.2016.09.007

33. Cook S, Weitzman M, Auinger P, Nguyen M, Dietz WH. Prevalence of a metabolic syndrome phenotype in adolescents: findings from the third National Health and Nutrition Examination Survey, 1988-1994. Arch Pediatr Adolesc Med. 2003;157(8):821-827. doi:10.1001/ archpedi.157.8.821

34. Gobato AO, Vasques AC, Zambon MP, Barros Filho Ade A, Hessel G. Metabolic syndrome and insulin resistance in obese adolescents. Rev Paul Pediatr. 2014;32(1):55-62. doi:10.1590/ S0103-05822014000100010

35. Redwine KM, Daniels SR. Prehypertension in adolescents: risk and progression. J Clin Hypertens (Greenwich). 2012;14(6):360-364. doi:10.1111/j.1751-7176.2012.00663.x

36. Falkner B, Gidding SS, Portman R, Rosner B. Blood pressure variability and classification of prehypertension and hypertension in adolescence. Pediatrics. 2008;122(2):238-242. doi:10.1542/peds.2007-2776

37. Redwine KM, Falkner B. Progression of prehypertension to hypertension in adolescents. Curr Hypertens Rep. 2012;14(6):619-625. doi:10.1007/s11906-012-0299-y

38. Fuentes RM, Notkola IL, Shemeikka S, Tuomilehto J, Nissinen A. Tracking of systolic blood pressure during childhood: a 15-year follow-up population-based family study in eastern Finland. J Hypertens. 2002;20(2):195-202. doi:10.1097/00004872-2002020 00-00008
39. Nandeesha H, Bobby Z, Selvaraj N, Rajappa M. Pre-hypertension: is it an inflammatory state? Clin Chim Acta. 2015;451(Pt B):338-342. doi:10.1016/j.cca.2015.10.022

40. Aristizabal JC, Estrada-Restrepo A, Barona J. Waist-to-height ratio may be an alternative tool to the body mass index for identifying Colombian adolescents with cardiometabolic risk factors. Nutr Hosp. 2019;36(1):96-102.

41. Lo K, Wong M, Khalechelvam P, Tam W. Waist-to-height ratio, body mass index and waist circumference for screening paediatric cardio-metabolic risk factors: a meta-analysis. Obes Rev. 2016;17 (12):1258-1275. doi:10.1111/obr.12456

42. Madruga JG, Moraes Silva F, Scherer Adami F. Positive association between waist-to-height ratio and hypertension in adolescents. Rev Port Cardiol. 2016;35(9):479-484. doi:10.1016/j.repc.2016. 03.004

43. Olza J, Aguilera CM, Gil-Campos M, et al. Waist-to-height ratio, inflammation and CVD risk in obese children. Public Health Nutr. 2014;17(10):2378-2385. doi:10.1017/S1368980013 003285

44. Vieira SA, Ribeiro AQ, Hermsdorff HHM, Pereira PF, Priore SE, Franceschini S. Waist-to-height ratio index or the prediction of overweight in children. Rev Paul Pediatr. 2018;36(1):7.

\section{Publish your work in this journal}

Diabetes, Metabolic Syndrome and Obesity: Targets and Therapy is an international, peer-reviewed open-access journal committed to the rapid publication of the latest laboratory and clinical findings in the fields of diabetes, metabolic syndrome and obesity research. Original research, review, case reports, hypothesis formation, expert opinion and commentaries are all considered for publication. The manuscript management system is completely online and includes a very quick and fair peer-review system, which is all easy to use. Visit $\mathrm{http}: / /$ www.dovepress.com/testimonials.php to read real quotes from published authors.

Submit your manuscript here: https://www.dovepress.com/diabetes-metabolic-syndrome-and-obesity-targets-and-therapy-journal 